\title{
Construction of Career Core Competence Evaluation System for Vocational Students Based on OBE
}

\begin{abstract}
Qishen Zhu and Yinghua Zha*
Nanjing Vocational University of Industry Technology

*Corresponding author. Email: zhayh@niit.edu.cn

ABSTRACT

Constructing an effective evaluation system of career core competence is an important link of talent training in higher vocational colleges and an important driving force of education and teaching reform to improve the quality of talent training. This paper puts forward the idea of constructing the career core competence evaluation system based on the concept of OBE. This paper discusses the evaluation system design from several aspects, such as the concept of career core competence, student outcome characteristics, construction principles, and evaluation organization. An evaluation system is established that takes career core competence as the first-level index, career method ability, and career social ability as the second-level indexes and detailed decomposition into nine third-level indexes. We find out the weight of all levels of index points in the evaluation system using the Delphi method and AHP, build the evaluation model of the career core competence of vocational college students.
\end{abstract}

Keywords: Career core competence, Evaluation system, OBE.

\section{INTRODUCTION}

China's development has deeply integrated into the globalization, which needs many high-quality, export-oriented engineering and technical talents. It is essential that talent training is in line with international standards. By joining the Washington Accord, undergraduate engineering education integrates the teaching standards of engineering education with international advanced educational ideas, cultivates technical talents that meet international engineering certification, and improves the global influence of China's engineering education. But higher vocational education lacks unified professional certification standards, and showed professional qualification certification lacks an international perspective. There is a big gap between the quality of talent training and market demand. Therefore, it is urgent to improve the advantages of vocational education in economic development.

The OBE-based education idea came from the basic education reform in the United States. After years of theoretical research and practical exploration, it has formed a complete theoretical system and is the mainstream idea of higher engineering education reform. We build the ability evaluation system of vocational students integrating the OBE idea and the "Sydney Accord" graduate quality requirements, and further improve the quality of vocational talent training. National Vocational Education Reform Implementation Plan issued by the State Council in January 2019 pointed out: reinforce the supervision evaluation of the quality of vocational education, and establish a vocational education quality evaluation system at the core of learners' professional ethics and technical skills. A scientific career core competence evaluation system plays a decisive role in improving the quality of vocational education, promoting the higher vocational education reform, and promoting the global flow of talents.

\section{CONCEPT DEFINITION}

\subsection{Outcome-based Education}

OBE education was proposed by American educator William g. Spady, who stressed that teaching practice should focus on the learning achievements of students [1]. Teaching implementation should take students as the center, create diversified teaching strategies, and meet the needs of personalized learning. According to the students' characteristics and individual differences, create the evaluation grade of the differences, timely 
evaluation, and accurately grasp the learning status of the students. Correct the teaching design and content in time, help students get a good learning experience, succeed in successful learning, and improve the initiative and innovation of students' learning.

The core of OBE includes student-centered, results-oriented, and continuous quality improvement. The outcome of OBE refers to the core competencies received by students after completing their studies, which are in line with the "Sydney Accord" graduate quality requirements. Graduate quality requirements reflect that talent training should focus on cultivating what can do, what to do, and what will do. While training students' professional abilities about professional knowledge, engineering practice, and others. They also underline the professional development method, social and other nonprofessional ability training.

\subsection{Career Core Competence}

The concept of career core competence originally appeared in Germany and was called key skills. It emphasized that while cultivating professional skills, we should pay attention to the cultivation of abilities such as method and society. The scholars gave a variety of expressions from the perspectives of competence and occupation, such as "core skills" in the UK, "basic skills" in the US, and "key skills" in Australia. Sheng Shudong and other scholars summarized the latest research results of career competence, interpreted the connotation of career core competence from the three dimensions of occupation, core, and ability. They considered that career core competence is the basic competence abstracted from all professional activities, and can be horizontally migrated and sustainable. It has the characteristics of implicit, universal, and ubiquitous $[2,3]$.

To conform to the development trend of international vocational education, the Ministry of Labor and Social Security, in combination with the vocational education system, made the "National Skills Revitalization Strategy" in 1998 [4]. It divides career ability into specific career ability, general industrial ability, and core career ability. The definition of career core competence is basic competence in addition to professional competence, falling into two categories, method competence and social competence. It includes communication and expression, digital computing, innovation, self-improvement, cooperation, problem-solving, information processing, and foreign-language application. Career core competence is the basis of carrying general industrial ability and specific career ability. It lies at the core position of the competence model and has universal applicability and extensive mobility [4]. Therefore, the meaning of career core competence is consistent with the expression of non-professional competence of the "Sydney Accord" graduate quality requirements. Career core competence as a vocational post' necessary condition has reached an agreement.

\subsection{Evaluation System of Career Core Competence}

Career core competence is the point of talent training quality in higher vocational education. The traditional assessments focus on basic vocational abilities such as professional knowledge and professional skills. Most of them carry out curriculum learning evaluation through classroom teaching practice and comprehensive training, lack of comprehensive evaluation of career core competence. However, only in the professional activities to solve complex problems can the core competence be reflected, which makes quantification and accurate assessment more difficult. Therefore, in the construction of a career core competence evaluation system of higher vocational students, we should follow the OBE idea, adopt the outcome-oriented reverse design, grasp the changes in job requirements, and determine the evaluation indicators with student development as the core. The application of statistical principles to determine the weight of evaluation indicators and the rational quantification of evaluation indicators are important research direction for determining the evaluation system.

\section{CONSTRUCT THE EVALUATION INDEX OF CAREER CORE COMPETENCE}

According to the evaluation method for the achievement of the "Sydney Accord" graduate quality requirements, the evaluation system should be student-centered. The evaluation indicators of learning achievements are refined based on graduate quality requirements and decomposed into guiding measurable indicator points. Based on the general standard of graduate quality requirements, coordinate the balanced relationship among the elements, indicators, and supporting courses of the evaluation system. According to the principles of science, development, and operability, combined with the qualitative and quantitative evaluation model, the evaluation system can truly reflect the quality of engineering education [6].

Based on the classification of career core competence in the "National Skills Revitalization Strategy" as the basis of the selection of evaluation indicators, we visited employers and industry experts, followed up and surveyed graduates, discussed with peers in many higher vocational colleges, and determined the indicators of career core competence 
through multiple surveys. The hierarchical structure of professional core competence is constructed by AHP, which is divided into first-level indexes, second-level indexes, and third-level indexes, which correspond to three levels of AHP goals, guidelines, and plans.

The evaluation system of career core competence includes two secondary indexes: career method competence and career social competence. Career method competence has shown five third-level indexes, which are innovation ability, problem-solving ability, information processing ability, foreign language application ability, and autonomous learning ability. Career social competence mainly refers to the ability of students to interact with classmates, integrate into the group and society, and set up four third-level indexes: language expression ability, communication and cooperation ability, psychological endurance ability, and duty performance ability.

In summary, the career core competence evaluation index system including 3 levels, 1 first-level levels, 2 second-level levels, and 9 third-level levels has been constructed, see Table 1.

\subsection{Career Method Ability}

Career method ability mainly refers to the ability of people to work and study methods in professional activities. The method ability of vocational students refers to the ability of students to acquire new knowledge and solve problems independently by collecting and processing information in the learning process. With the ability to master these methods, students can apply the acquired knowledge and experience to practice and learning in unknown areas. It embodies the potential of students' career development, mainly including multi-dimensional ability combinations such as autonomous learning, information processing, problem-solving, foreign language application, and innovation.

Autonomous learning ability mainly includes lifelong learning consciousness, good learning habits, and learning methods. Stimulate students' curiosity by establishing correct learning goals and motivation. A clear learning plan and learning path can help students develop good learning habits. Help students complete their learning goals through timely evaluation and feedback. In the information age, the ability to collect high-quality resources is becoming more and more important.

The problem-solving ability has always been the basic skill of social survival. Building problem awareness can anticipate potential problems. The ability to correctly describe problems is particularly important for students who are new to the workplace. Turning knowledge into the experience by solving problems can help students understand professional knowledge more deeply and deepen professional abilities.

With the national innovation strategy put forward, innovation consciousness, innovation thinking, and innovation ability have become the new topic of talent training and education reform. It is an effective way to inspire students to think more, find more and practice more, stimulate innovation desire in practice, and guide students' innovation through innovation courses, innovation projects, and results-oriented reforms.

\subsection{Career Social Ability}

Career social ability refers to a person's social cognition, teamwork, interpersonal communication, etc. It includes language expression, communication and cooperation, adaptability, and performance of duties. Language expression is the basic social ability to understand the views of others and express their views.

Communication and cooperation are the survival ability of social groups, mainly including communication and cooperation skills, timely feedback on communication and work tasks, cooperation consciousness, and mutual assistance in teamwork. Psychological bearing ability includes the ability to recognize and tolerate setbacks, the ability to eliminate interference, and the ability to self-stress.

Fulfilling duties is the social responsibility, professional responsibility, and ability to abide by professional ethics that students must have to become a social person. They can understand the meaning and value of life manage and adjust their emotions.

Table 1. Career core competence evaluation index system

\begin{tabular}{|l|l|l|}
\hline First-level index (target level) & Second-level index (criteria level) & Third-level index (plan level) \\
\hline \multirow{4}{*}{ Career core competence } & \multirow{4}{*}{ Method competence $\left(\mathrm{C}_{1}\right)$} & Innovation $\left(\mathrm{C}_{11}\right)$ \\
& & Problem-solved $\left(\mathrm{C}_{12}\right)$ \\
\cline { 3 - 3 } & & Information processing $\left(\mathrm{C}_{13}\right)$ \\
\cline { 3 - 3 } & & Foreign language application $\left(\mathrm{C}_{14}\right)$ \\
\cline { 3 - 3 } & \multirow{3}{*}{ Social competence $\left(\mathrm{C}_{2}\right)$} & Autonomous learning $\left(\mathrm{C}_{15}\right)$ \\
\cline { 3 - 3 } & & Language expression $\left(\mathrm{C}_{21}\right)$ \\
\cline { 3 - 3 } & & Communication and cooperation $\left(\mathrm{C}_{22}\right)$ \\
\cline { 3 - 3 } & & Mental capacity $\left(\mathrm{C}_{23}\right)$ \\
\cline { 3 - 3 } & & Perform duties $\left(\mathrm{C}_{24}\right)$ \\
\hline
\end{tabular}




\section{DETERMINING THE EVALUATION INDEX WEIGHT OF CAREER CORE COMPETENCE}

\subsection{Decision Method for Evaluating Index System Weight}

The weight of the evaluation index represents the relative importance of this index in the index system, which is an important part of constructing a scientific evaluation index system [6]. Therefore, the Delphi Method and the Analytic Hierarchy Process (AHP) are used to quantify the quantitative evaluation indexes of qualitative description, to ensure the accuracy of the quantitative results, and then get the final evaluation of students' career core competence.

Delphi method predicts by consulting experts anonymously, and after many times of repeated consultation. The experts' opinions are consistent and got the collective evaluation results with high accuracy finally. The AHP method proposed by T.L.Saaty, an American operations researcher is a decision analysis method for combining qualitative and quantitative. It builds a hierarchical model by layering complex problems. Then find out the judgment matrix feature vector, called on to judge the correlation of factors at the same level, and use consistency test to judge the weight of the comparison of signs. Finally, solve the relative weight value, use the weighted sum method to calculate the weight of the total target as the basis for evaluation and decision-making. Set the importance degree between two evaluation signs of the same level in the scale of numbers $1 \sim 9$, see Table 2 [7].

\subsection{Calculation of the Second-level Evaluation Index Weight}

In the evaluation index system in Table 1, there are two first-level indexes, and the weight value can be determined by the Delphi method. According to the evaluation principles, we selected four employers, four industry experts, three alumni, four school experts to send questionnaires for statistical processing. After three rounds of consultation and feedback, the average deviation is within \pm 0.03 , showing the opinions of the expert group are almost the same, as shown in Table 3. From the data in the table, it can be seen that career method ability and career social ability are almost equally important in vocational activities.

\subsection{Calculation of the Third-level Evaluation Index Weight}

The third-level evaluation index uses the AHP method to calculate the weight, and we invited 15 stakeholders to score each index by pairwise comparison at the same level. We get the value of the judgment matrix about career method competence of innovation ability, problem-solving ability, information processing ability, foreign language application ability, and autonomous learning ability. We get the value of the judgment matrix about career social competence of language expression, communication and cooperation, psychological acceptance, and performance of duties. Tables 4 and 5 show the relative weight ratio of the third-level indexes of one expert.

According to the data in Table 4 and Table 5, build the corresponding judgment matrix, as shown in Formula 1 and Formula 2.

$\begin{aligned} C_{1} & =\left[\begin{array}{ccccc}1 & 1 / 3 & 2 & 3 & 1 / 3 \\ 3 & 1 & 3 & 3 & 1 / 2 \\ 1 / 2 & 1 / 3 & 1 & 2 & 1 / 3 \\ 1 / 3 & 1 / 3 & 1 / 2 & 1 & 1 / 3 \\ 3 & 2 & 3 & 3 & 1\end{array}\right] \\ C_{2} & =\left[\begin{array}{cccc}1 & 2 & 2 & 3 \\ 3 & 1 & 3 & 3 \\ 1 / 2 & 1 / 3 & 1 & 2 \\ 1 / 3 & 1 / 3 & 1 / 2 & 1\end{array}\right]\end{aligned}$

Table 2. Definition of the scale value of the judgment matrix

\begin{tabular}{|l|l|l|}
\hline Scale value & Definition & Explanation \\
\hline 1 & Equal important & $\mathrm{a}_{\mathrm{i}}$ and $\mathrm{a}_{\mathrm{j}}$ contribute equally to the objective \\
\hline 3 & Moderate important & judgment moderately favor $\mathrm{a}_{\mathrm{i}}$ over $\mathrm{a}_{\mathrm{j}}$ \\
\hline 5 & Strong important & judgment strongly favor $\mathrm{a}_{\mathrm{i}}$ over $\mathrm{a}_{\mathrm{j}}$ \\
\hline 7 & Very strong important & $\mathrm{a}_{\mathrm{i}}$ is favored very strongly over $\mathrm{a}_{\mathrm{j}}$ \\
\hline 9 & Extreme important & $\mathrm{a}_{\mathrm{i}}$ is favored highest possible over $\mathrm{a}_{\mathrm{j}}$ \\
\hline $2,4,6,8$ & Express intermediate values & $\mathrm{a}_{\mathrm{i}}$ and $\mathrm{a}_{\mathrm{j}}$ are very close in importance \\
\hline
\end{tabular}


Table 3. The weight coefficient of the second-level index

\begin{tabular}{|l|c|c|}
\hline & Career method component $\mathbf{(}_{\mathbf{1}} \mathbf{)}$ & Career method component $\left(\mathbf{C}_{\mathbf{2}}\right)$ \\
\hline First-time weight & 0.65 & 0.35 \\
\hline Maximum deviation & 0.10 & -0.10 \\
\hline Second-time weight & 0.583 & 0.417 \\
\hline Maximum deviation & -0.021 & 0.025 \\
\hline Weight \% & 58.3 & 41.7 \\
\hline
\end{tabular}

Table 4. Judgment matrix $\mathrm{C}_{1}$ of third-level indexes of career method ability

\begin{tabular}{|l|l|l|l|l|l|}
\hline & $\begin{array}{l}\text { innovation } \\
\mathbf{C}_{\mathbf{1 1}}\end{array}$ & $\begin{array}{l}\text { problem-solving } \\
\mathbf{C}_{\mathbf{1 2}}\end{array}$ & $\begin{array}{l}\text { information } \\
\text { processing } \\
\mathbf{C}_{\mathbf{1 3}}\end{array}$ & $\begin{array}{l}\text { foreign } \\
\text { language } \\
\text { application } \\
\mathbf{C}_{\mathbf{1 4}}\end{array}$ & $\begin{array}{l}\text { autonomous } \\
\text { learning } \mathbf{C}_{\mathbf{1 5}}\end{array}$ \\
\hline innovation $\mathrm{C}_{11}$ & 1 & $1 / 3$ & 2 & 3 & $1 / 3$ \\
\hline problem-solving $\mathrm{C}_{12}$ & 3 & 1 & 3 & 3 & $1 / 2$ \\
\hline information processing $\mathrm{C}_{13}$ & $1 / 2$ & $1 / 3$ & 1 & 2 & $1 / 3$ \\
\hline $\begin{array}{l}\text { foreign language application } \\
\mathrm{C}_{14}\end{array}$ & $1 / 3$ & $1 / 3$ & $1 / 2$ & 1 & $1 / 3$ \\
\hline autonomous learning $\mathrm{C}_{15}$ & 3 & 2 & 3 & 3 & 1 \\
\hline
\end{tabular}

Table 5. Judgment matrix $\mathrm{C}_{2}$ of third-level indexes of career social ability

\begin{tabular}{|l|l|l|l|l|}
\hline & $\begin{array}{l}\text { language } \\
\text { expression } \mathbf{C}_{21}\end{array}$ & $\begin{array}{l}\text { communication } \\
\mathbf{C}_{22}\end{array}$ & $\begin{array}{l}\text { psychological } \\
\text { acceptance } \mathbf{C}_{23}\end{array}$ & $\begin{array}{l}\text { performance of } \\
\text { duties } \mathbf{C}_{24}\end{array}$ \\
\hline language expression $\mathrm{C}_{21}$ & 1 & 2 & 2 & $1 / 2$ \\
\hline communication $\mathrm{C}_{22}$ & $1 / 2$ & 1 & 3 & $1 / 2$ \\
\hline psychological acceptance $\mathrm{C}_{23}$ & $1 / 2$ & $1 / 3$ & 1 & $1 / 3$ \\
\hline performance of duties $\mathrm{C}_{24}$ & 2 & 2 & 3 & 1 \\
\hline
\end{tabular}

After getting the judgment matrix $\mathrm{C}$ of the method competence, use SPSS software to handle the matrix. The maximum feature value of the judgment matrix $\mathrm{C}_{1}$ is $\lambda_{\max }=5.212$, and the maximum feature vector $\mathrm{WC}_{1}=$ $(0.1618,0.2826,0.0942,0.0903,0.3711)$. The weight of career method competence is 0.583 , so the weights of the five third-level indexes are $9.43 \%, 16.48 \%, 5.49 \%$, $5.26 \%$, and $21.64 \%$.

Using the same method, the maximum feature value of the judgment matrix $\mathrm{C}_{2}$ for social competence is $\lambda_{\max }=4.143$, and the maximum feature vector $\mathrm{WC}_{2}=$ $(0.2654,0.2150,0.1104,0.4092)$. The weight of career social competence is 0.417 , so the weights of the four third-level indexes are $11.07 \%, 8.97 \%, 4.60 \%$, and $17.06 \%$.

Because the indexes are a comparison between one another, the data could be inconsistent. AHP calculates the consistency ratio $\mathrm{CR}$ of weight $\mathrm{W}$ through $\mathrm{CR}=\mathrm{CI} / \mathrm{RI}$. CI is the consistency index (Consistency Index, referred to as $\mathrm{CI}$ ) for single-level ranking, and the calculation formula is $\mathrm{CI}=\left(\lambda_{\max }-n\right) /(\mathrm{n}-1)$. RI is a random consistency index, the value showing in Table 6 . The judgment matrix satisfies the consistency when $\mathrm{CR}<0.1$; the judgment matrix deviates from the consistency if $\mathrm{CR}>0.1$, it is necessary to re-use the Delphi method to adjust the index. According to the formula calculation, the $\mathrm{CR}$ of the judgment matrices $\mathrm{C}_{1}$ and $\mathrm{C}_{2}$ are 0.0474 and 0.0536 , which are both less than
0.1. This shows that both judgment matrices are consistent and effective.

Table 6. Random consistency indicator RI

\begin{tabular}{|l|l|l|l|l|l|l|}
\hline dimension & $\mathbf{3}$ & $\mathbf{4}$ & $\mathbf{5}$ & $\mathbf{6}$ & $\mathbf{7}$ & $\mathbf{8}$ \\
\hline RI & 0.58 & 0.96 & 1.12 & 1.24 & 1.32 & 1.41 \\
\hline
\end{tabular}

Through analysis and calculation, we can see the consciousness of learning vocational methods and abilities has the highest weight. Once students have a sense of learning, they can develop the philosophy and habits of lifelong learning. They will have a first-mover advantage in career development and can quickly adapt to new technological changes. The weight of analysis, problem-solving, and innovation awareness is also high, which further shows the ability to analyze and solve problems is the most basic competence in daily life and work. This is also the basic goal of training students in Higher Vocational Colleges and the direction of educational reform. Physical and mental health occupies the largest weight of career social ability, showing that college students are in the critical period of forming outlook on life and the world. Bringing ideological and political education into the whole process of talent training will have a far-reaching impact on students to set up a correct and positive outlook on life. 


\section{CONCLUSION}

This study adopts the career core competence definition by "National Skills Revitalization Strategy" based on the OBE education idea. Through a literature analysis and questionnaire survey, we have reviewed the basic ideas and evaluation system of the career core competence. This paper builds the third-level evaluation system of career core competence of vocational college students based on OBE and discovers the weight of each evaluation index by combining the Delphi method and AHP. The design and calculation of index weight in this study have a certain theoretical basis and operability, which provide an effective reference for the cultivation of career core competence of vocational college students. However, since the quality of an evaluation depends on the subjective viewpoint of the evaluation subject, further practice is needed to verify its science and integrity, which is also the next research direction of this study.

\section{ACKNOWLEDGMENTS}

This research was supported by the 13th Five-Year Plan for Education Science in Jiangsu Province in 2018, "The Construction of Core Competence Monitoring Indicators for Higher Vocational Students under the Framework of the Sydney Agreement -Based on Computer Specialty" (No. B-b/2018/03/10)

\section{REFERENCES}

[1] Morcke, Anne Mette, Tim Dornan, and Berit Eika., Outcome (competency) based education: an exploration of its origins, theoretical basis, and empirical evidence. Advances in Health Sciences Education 18.4 (2013): 851-863.
[2] Sheng, Shudong., A New Interpretation of the Connotation of Career Core Competence and Its Structure. Education and Vocation 24(2013): 18-20.

[3] Meijers, Frans, et al. "A dialogue worth having: vocational competence, career identity and a learning environment for twenty-first century success at work." Enhancing Teaching and Learning in the Dutch Vocational Education System. Springer, Cham, 2017: 139-155.

[4] Duan, Shengxian., Research on the Characteristics and Methods of Cultivating College Students' Vocational Core Competence. 2nd International Conference on Contemporary Education, Social Sciences and Ecological Studies (CESSES 2019). Atlantis Press, 356(2019): 169-172.

[5] Liu Hui, Zhu Kai, Wang Xinqun, et al. Construction of the OBE-Based Evaluation System of the Achievement of Graduation Attributes [J]. Advances in Education, 8.6(2018): 649-659.

[6] Guo, Xingming, and Youyi Chai., Vocational students' professional ability: quantitative reconstruction and evaluation. International Journal of Continuing Engineering Education and Life Long Learning 28.2 (2018): 156-168.

[7] Jiang, Li, Yan Li, and Cheng Jiang., Employment competitiveness of college students based on improved AHP. Eurasia Journal of Mathematics, Science and Technology Education 13.8 (2017): $5225-5232$. 